\title{
Origin of Broad-Band Emission and Impact of Structural Dimensionality in Tin-Alloyed Ruddlesden-Popper Hybrid Lead Iodide Perovskites
}

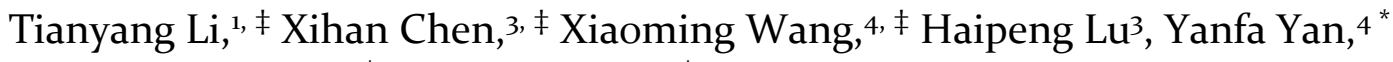 \\ Matthew C. Beard, $3^{*}$ David B. Mitzi ${ }^{1,2}$ * \\ ${ }^{1}$ Department of Mechanical Engineering and Material Science, Duke University, Durham, North \\ Carolina 27708, United States \\ 2 Department of Chemistry, Duke University, Durham, North Carolina 27708, United States \\ 3 Chemistry and Nano Science Center, National Renewable Energy Laboratory, Golden, Colorado \\ 80401, United States \\ ${ }^{4}$ Department of Physics and Astronomy and Wright Center for Photovoltaics Innovation and \\ Commercialization, The University of Toledo, Toledo, Ohio 43606, United States
}

Chemicals. Phenethylammonium iodide (PEAI, Greatcell Solar), SnI 2 (99.99\%, Sigma Aldrich), methylammonium iodide (MAI, Greatcell Solar), $\mathrm{PbI}_{2}$ (99.99\%, TCI), hypophosphorous acid solution (50 wt\%, Sigma Aldrich) and hydriodic acid (HI) solution ( $57 \mathrm{wt} \%$, stabilized, 99.95\%, Sigma Aldrich) were used without further purification.

Synthesis. $n=1$ crystals were synthesized by slowly cooling a $1.0 \mathrm{~mL}$ o.1 M HI solution containing stoichiometric amounts of $\mathrm{PbI}_{2}$ and PEAI, from $90{ }^{\circ} \mathrm{C}$ to room temperature over 48 hours. For $n=1$ crystals synthesized in nominally $\mathrm{I}_{2}$-free $\mathrm{HI}$ solution, an additional $0.1 \mathrm{ml}$ of hypophosphorous acid solution is added into the $1.0 \mathrm{~mL} \mathrm{HI}$ solution and the solution is heated at $90{ }^{\circ} \mathrm{C}$ for 30 minutes prior to cooling down to room temperature. For $n=1$ crystals synthesized by antisolvent diffusion methods, dichloromethane is used as the antisolvent and slowly diffuses into a $0.1 \mathrm{M}$ dimethylformamide solution containing stoichiometric amounts of $\mathrm{PbI}_{2}$ and PEAI over 2 days. $n=2$ and 3 crystals were grown based on a previously reported cooling method. ${ }^{1}$ Generally, $\mathrm{PbI}_{2}, \mathrm{MAI}$, and PEAI with specific ratios were dissolved in hydriodic acid solution at $90^{\circ} \mathrm{C}$, followed by slowly cooling the solution to room temperature over 48 hours. The ratios of $\mathrm{PbI}_{2}, \mathrm{MAI}$, PEAI for $n=2,3$ are, 0.2/0.6/0.033 mmol, 0.333/o.8/o.033 mmol, respectively, in $1 \mathrm{~mL}$ of HI solution. Sn alloyed crystals were grown similarly as pristine crystals, except stoichiometric amount of $\mathrm{PbI}_{2}$ is substituted by $\mathrm{SnI}_{2}$. As-grown crystals were carefully isolated from the parent solution and then dried under vacuum.

\section{Characterization methods.}

Powder X-ray diffraction (XRD) measurements were carried out on a PANalytical Empyrean Powder $\mathrm{X}$-ray diffractometer using $\mathrm{CuK} \alpha$ radiation, with $\mathrm{X}$-ray tube operating condition at $45 \mathrm{kV}$ and $40 \mathrm{~mA}$.

Single crystal diffraction data were collected on a Bruker D8 ADVANCE Series II instrument, all at room temperature, using Mo K $\alpha$ radiation $(\lambda=0.71073 \AA)$.

Steady state photoluminescence measurements were performed on a Horiba Jobin Yvon LabRam ARAMIS system using a $442 \mathrm{~nm}$ laser as excitation.

Photoluminescence quantum yield was determined with an inVia Renishaw confocal Raman microscope with a $532 \mathrm{~nm}$ laser. A $\mathrm{CsPbI}_{3}$ nanocrystal film with $6 \%$ quantum yield was used as internal standard. Integrated area was used to determine the PL quantum yield for $1 \%$ Sn alloyed $n=$ 1,2 and 3 samples. The samples were kept in an air-free holder and PL was collected by a $20 \times$ objective lens with $0.05 \%$ laser intensity $(\sim 0.005 \mathrm{~mW})$. 
The transient reflection measurement is based on a Ti:sapphire laser amplifier (Continuum Integra, 8oonm, pulse duration $\sim 10 \mathrm{fs}, \sim 3 \mathrm{~mJ} /$ pulse and $1 \mathrm{kHz}$ repetition rate) and a pump-probe transient reflection spectrometer (Helios, Ultrafast System). The fundamental beam (8oonm) is split into two beams. One beam is sent to an optical parametric amplifier to generate the pump pulse with tunable wavelength, and its intensity is attenuated by two neutral density filter wheels. The other $800 \mathrm{~nm}$ beam is focused into a sapphire to generate the white light probe. Probe delay can be up to $\sim 2 \mathrm{~ns}$ and is tuned by a delay line. The pump and probe are focused and overlapped onto the sample. The probe size is $\sim 200 \mu \mathrm{m}$, and pump beam size is $\sim 590 \mu \mathrm{m}$. The pump beam is incident normal to the sample and the probe beam is incident 45 degree to the sample. The beam size is defined as the radius of an aperture that contains $\left(1 / \mathrm{e}^{2}\right)$ of the total power. All samples were measured under ambient conditions.

Normalized kinetics in Figure 3 is fitted with 3 different processes: hole trapping (exponential decay), spectra broadening (exponential rise) and electron localization (exponential decay). Each process is represented by an exponential decay/rise. Also, the decay of the exciton is accompanied by a rise of the trap state-i.e., the two kinetics are related. Therefore, excitons (orange curve in Figure $3 f$ ) and trap states (blue curve in Figure $3 \mathrm{f}$ ) will be fitted together with the following function:

$$
\begin{gathered}
\text { Trap: } \frac{\Delta R}{R} \sim\left(1-A_{0} e^{-\frac{t}{\tau_{0}}}\right)(\text { hole trapping })+A_{1} e^{-\frac{t}{\tau_{1}}}(\text { spectra shift }) \\
+A_{2} e^{-\frac{t}{\tau_{2}}}(\text { electron localization }) \\
\text { Exciton: } \frac{\Delta R}{R} \sim A_{0} e^{-\frac{t}{\tau_{0}}}(\text { hole trapping })+\left(1-A_{1} e^{-\frac{t}{\tau_{1}}}\right)(\text { spectra shift }) \\
+A_{3} e^{-\frac{t}{\tau_{3}}}(\text { exciton decay })
\end{gathered}
$$

where $A_{o}$ represents the amplitude for trapped hole and to represents the ultrafast trapping time. The fitting gives $\tau_{0} \approx 0.5 \mathrm{ps}$. $A_{1}$ represents the amplitude for spectra shift and $\tau_{1}$ represents the time constant of spectra shift. The fitting gives $\tau_{1} \approx 9 \mathrm{ps}$. $\mathrm{A}_{2}$ represents the amplitude for electron localization and $\tau_{2}$ represents the time constant. The fitting gives $\tau_{2} \approx 1 \mathrm{~ns}$.

DFT details. Density functional theory (DFT) calculations were performed using the VASP code.-3 The interaction between ions and electrons was described by the projector augmented wave method. ${ }^{4} \mathrm{~A}$ kinetic energy cutoff of $300 \mathrm{eV}$ was used for the plane-wave basis. Experimental lattice parameters were used, while the atomic positions were fully relaxed until the residual forces were less than $0.01 \mathrm{eV} / \AA$. The ground- and excited-state structure optimization as well as the exciton emission energy were calculated by using the hybrid PBEo functional..$^{-6}$ The total energy of an exciton was calculated by constrained occupation DFT.7 Spin-orbit coupling effect was included in the calculations. 


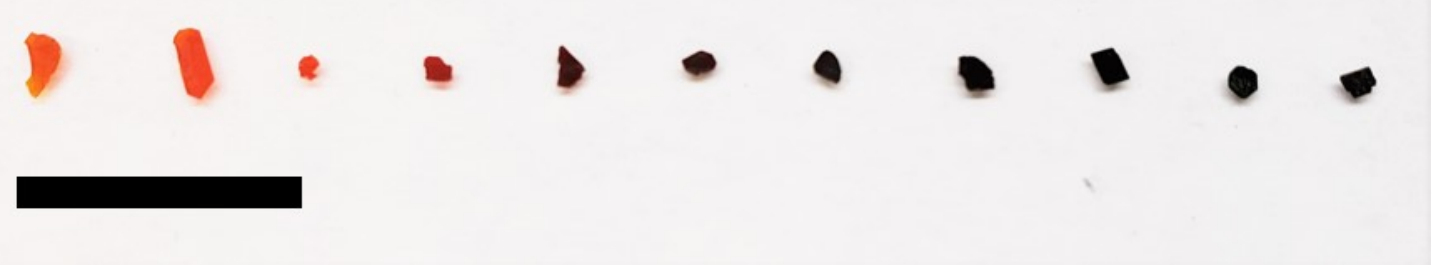

Figure S1. Crystals of $\mathrm{PEA}_{2} \mathrm{PbI}_{4}$ with o\%, o.01\%, o.1\%, 1\%, 2\%, 5\%, 15\%, 25\%, 50\%, $75 \%$ and 100\% Sn from left to right, scale bar: $10 \mathrm{~mm}$.

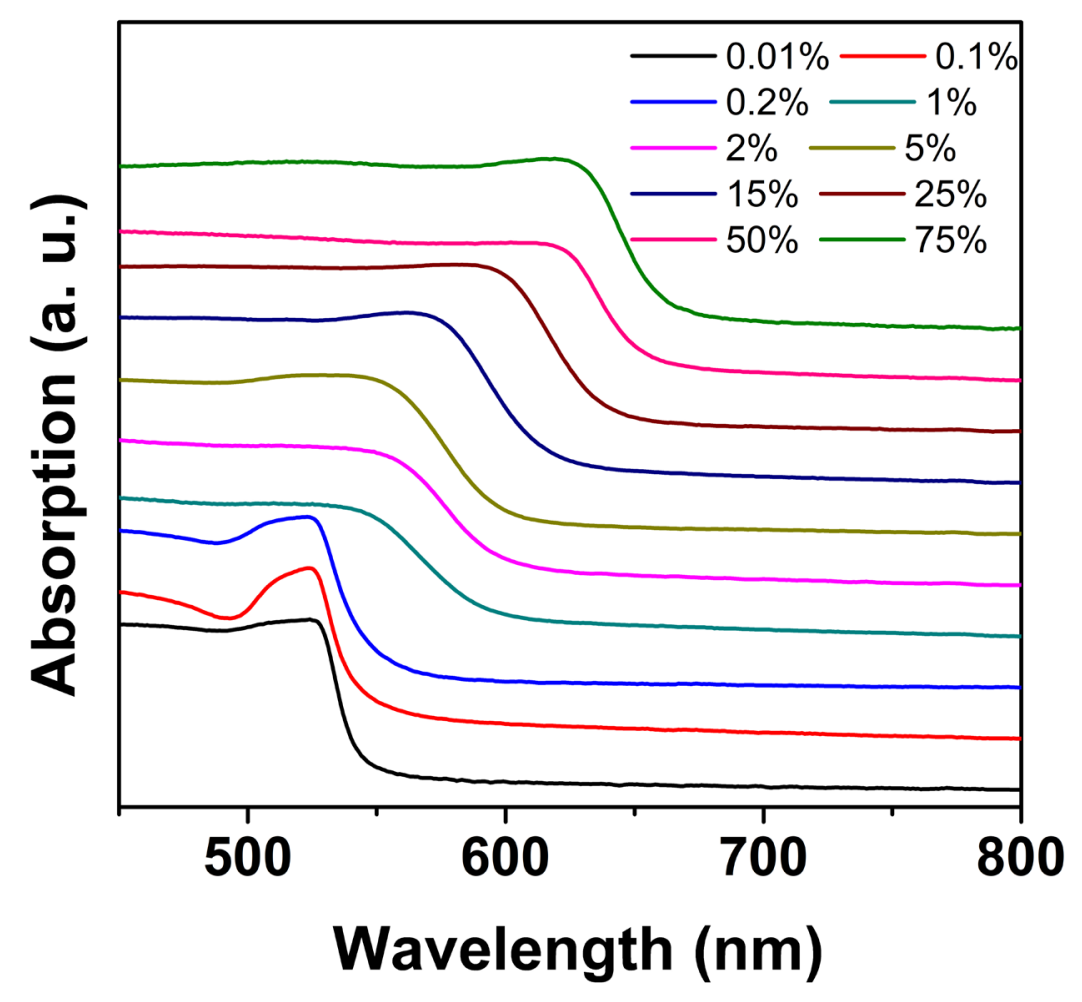

Figure S2. Absorption spectra of exfoliated crystals of $\mathrm{PEA}_{2} \mathrm{PbI}_{4}$ with $0.01 \%, 0.1 \%, 0.2 \%, 1 \%, 2 \%, 5 \%$, $15 \%, 25 \%, 50 \%, 75 \%$ and $100 \% \mathrm{Sn}$. The lack of the excitonic absorption peak is due to the large thickness of the exfoliated crystal flakes. 
Table S1. Sn content (refined using various techniques) and crystallographic parameters of $\mathrm{PEA}_{2} \mathrm{PbI}_{4}$ crystals with different targeted $\mathrm{Sn} \%$ alloying

\begin{tabular}{|c|c|c|c|c|c|c|c|}
\hline \multicolumn{3}{|c|}{$\mathrm{Sn} \%$} & \multirow{2}{*}{$\begin{array}{l}\text { Space } \\
\text { group }\end{array}$} & \multirow{2}{*}{$a(\AA ̊) / \alpha$} & \multirow{2}{*}{$b(\AA) / \beta$} & \multirow{2}{*}{$c(\AA) / \gamma$} & \multirow{2}{*}{$V\left(\AA^{3}\right)$} \\
\hline $\begin{array}{l}\text { Target in } \\
\text { solution }\end{array}$ & $\begin{array}{l}\text { ICP- } \\
\text { MS }\end{array}$ & $\begin{array}{l}\text { SC- } \\
\text { XRD }\end{array}$ & & & & & \\
\hline o & $\mathrm{o}$ & o & $\mathrm{P}-1$ & $\begin{array}{l}8.7438(12) \\
84.637(5)^{\circ}\end{array}$ & $\begin{array}{l}8.7518(13) \\
84.640(5)^{\circ}\end{array}$ & $\begin{array}{c}33.028(5) \\
89.638(5)^{\circ}\end{array}$ & $2505.4(6)$ \\
\hline 0.02 & 0.04 & - & - & - & - & - & - \\
\hline 0.1 & 0.16 & - & - & - & - & - & - \\
\hline 1 & 2.6 & 2.3 & $P-1$ & $\begin{array}{c}8.7434(2) \\
84.6354(6)^{\circ}\end{array}$ & $\begin{array}{c}8.7452(2) \\
84.6262(6)^{\circ}\end{array}$ & $\begin{array}{c}33.0154(7) \\
89.6346(6)^{\circ}\end{array}$ & $2502.3(1)$ \\
\hline 5 & 5.9 & 6.5 & Cc & $\begin{array}{c}12.4091(3) \\
90^{\circ}\end{array}$ & $\begin{array}{c}12.3273(3) \\
93.2442(8)^{\circ}\end{array}$ & $\begin{array}{c}32.7738(8) \\
90^{\circ}\end{array}$ & $5005 \cdot 4(2)$ \\
\hline 15 & $15 \cdot 3$ & 15.4 & Cc & $\begin{array}{c}12.3962(3) \\
90^{\circ}\end{array}$ & $\begin{array}{c}12.3206(2) \\
93.2367(7)^{\circ}\end{array}$ & $\begin{array}{c}32.7610(7) \\
90^{\circ}\end{array}$ & $4995.56(18)$ \\
\hline 25 & 27.5 & 26.7 & $\mathrm{Cc}_{\mathrm{c}}$ & $\begin{array}{c}12.3890(2) \\
90^{\circ}\end{array}$ & $\begin{array}{c}12.3097(2) \\
93.2420(6)^{\circ}\end{array}$ & $\begin{array}{c}32.7607(6) \\
90^{\circ}\end{array}$ & $4988.17(15)$ \\
\hline 50 & $57 \cdot 3$ & 53.6 & Cc & $\begin{array}{c}12.3743(3) \\
90^{\circ}\end{array}$ & $\begin{array}{c}12.2955(2) \\
93.2483(7)^{\circ}\end{array}$ & $\begin{array}{c}32.7370(7) \\
90^{\circ}\end{array}$ & $4972.87(18)$ \\
\hline 75 & 77.5 & 76.6 & Cc & $\begin{array}{c}12.3610(3) \\
90^{\circ}\end{array}$ & $\begin{array}{c}12.2836(2) \\
93.2500(8)^{\circ}\end{array}$ & $\begin{array}{c}32.7204(7) \\
90^{\circ}\end{array}$ & $4960.20(18)$ \\
\hline $100^{8}$ & - & 100 & $\mathrm{C}_{2} / \mathrm{m}$ & $\begin{array}{c}32.640(1) \\
90^{\circ}\end{array}$ & $\begin{array}{c}6.117(3) \\
93.214(9)^{\circ}\end{array}$ & $\begin{array}{c}6.164(3) \\
90^{\circ}\end{array}$ & 1228.7 \\
\hline
\end{tabular}




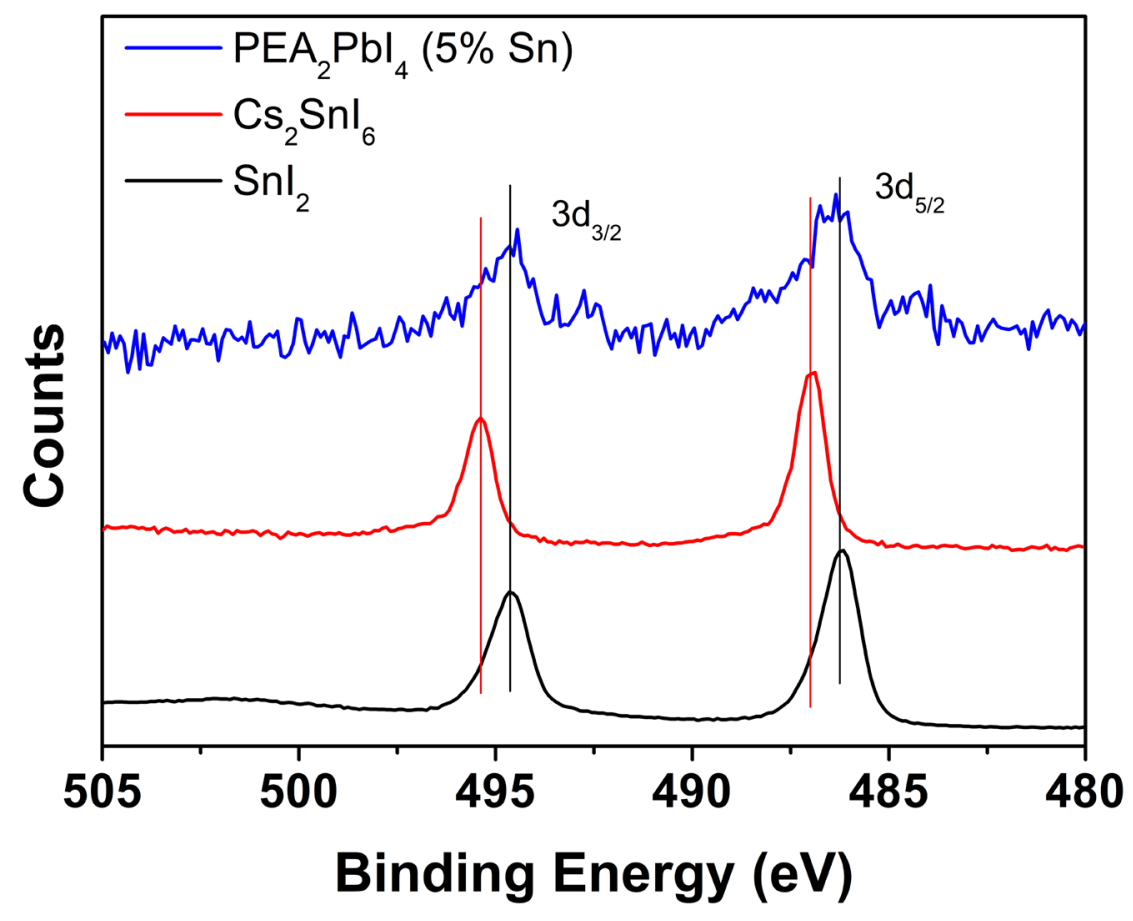

Figure S3. XPS spectra showing $\mathrm{Sn}_{3} \mathrm{~d}$ peaks in $5 \% \mathrm{Sn} \mathrm{PEA}_{2} \mathrm{PbI}_{4}$ sample with $\mathrm{SnI}_{2}$ and $\mathrm{Cs}_{2} \mathrm{SnI}_{6}$ as references

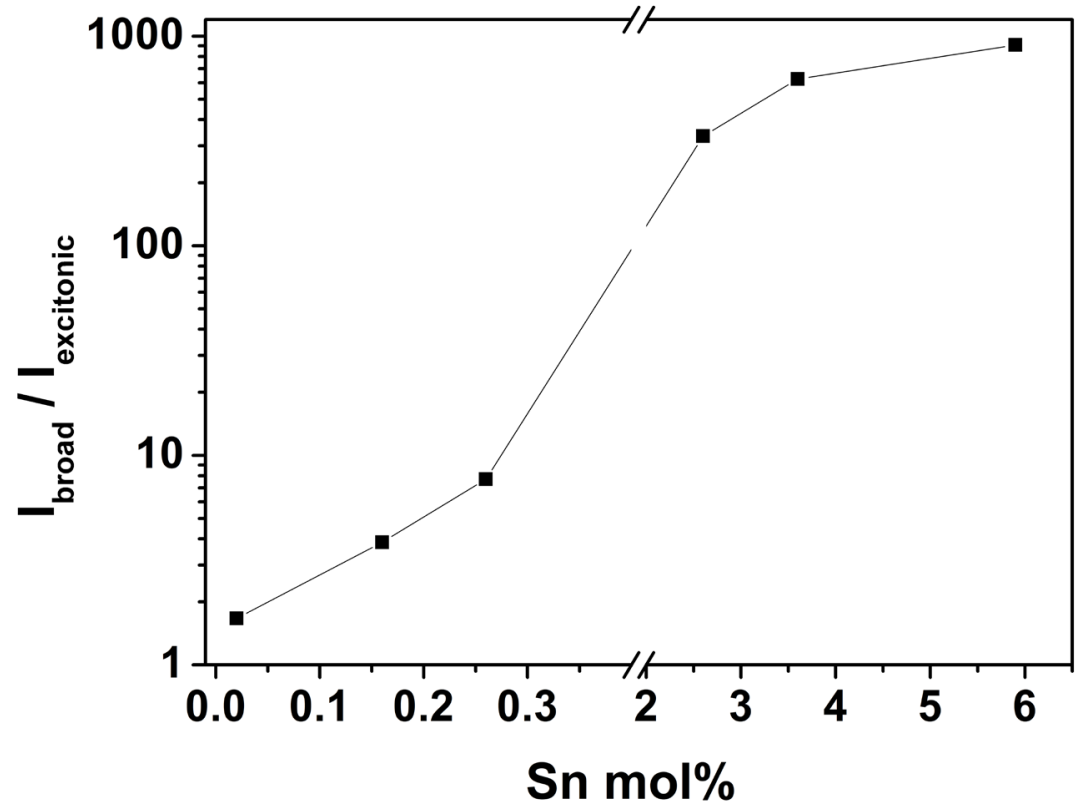

Figure $\mathbf{S}_{4}$. Intensity ratio of broad-band and excitonic PL at different $\mathrm{Sn} \%$ in $\mathrm{PEA}_{2} \mathrm{PbI}_{4}$ crystals using $442 \mathrm{~nm}$ laser as excitation 


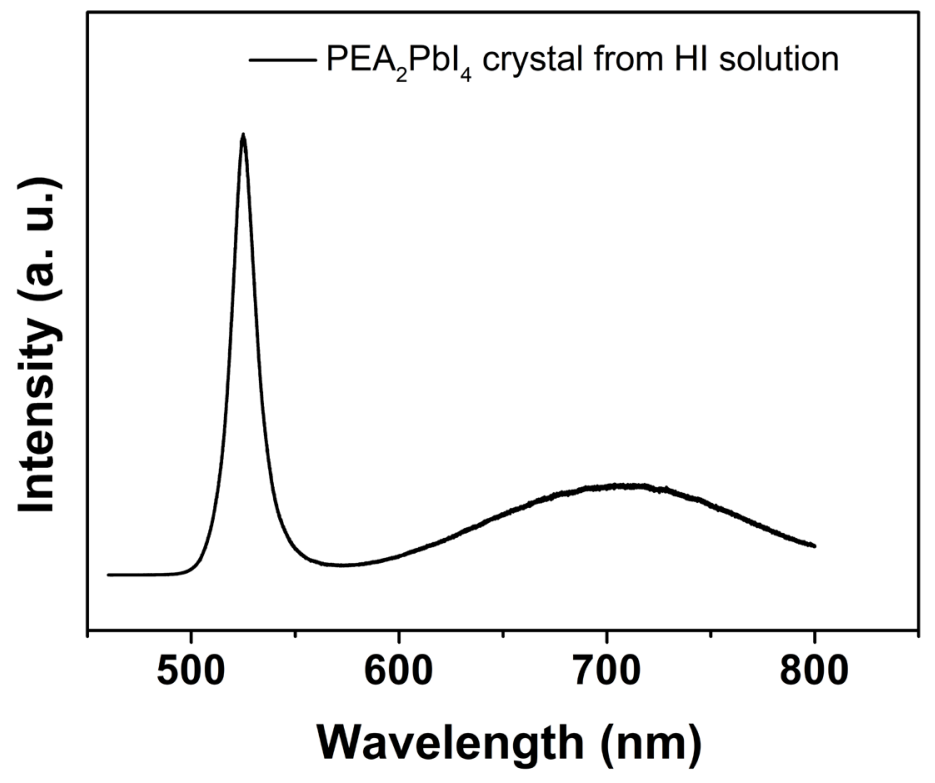

Figure $\mathrm{S}_{5}$. PL spectrum of $\mathrm{PEA}_{2} \mathrm{PbI}_{4}$ crystals made from $\mathrm{HI}$ solution with hypophosphorous acid as reducing agent, using $442 \mathrm{~nm}$ laser as excitation.

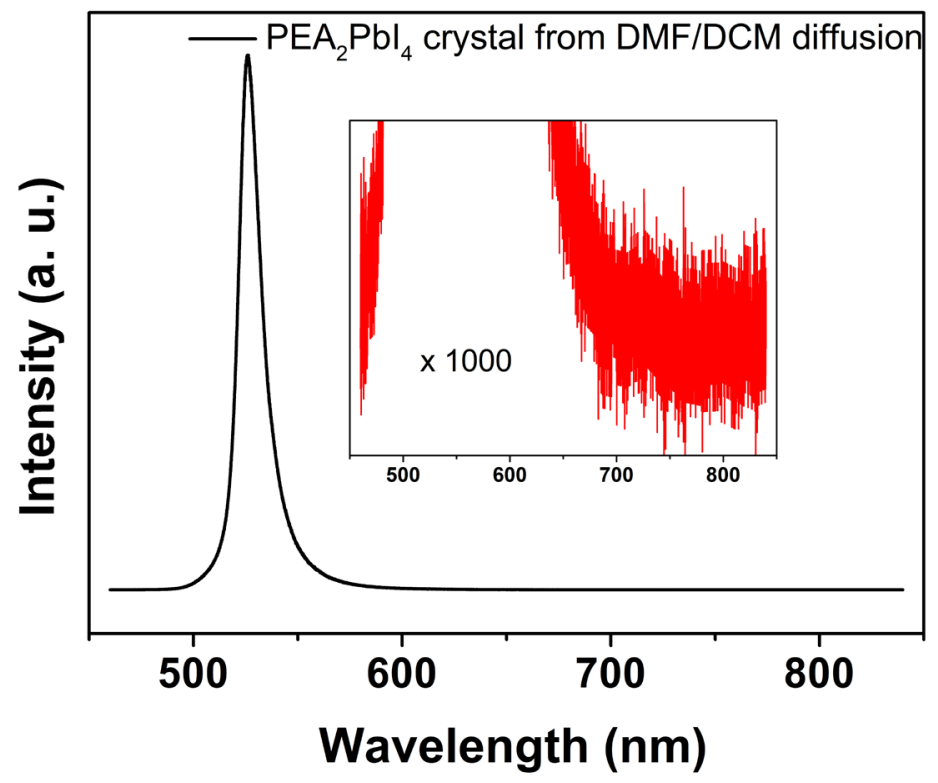

Figure S6. PL spectrum of $\mathrm{PEA}_{2} \mathrm{PbI}_{4}$ crystals made from diffusion of dichloromethane into dimethylformamide. 

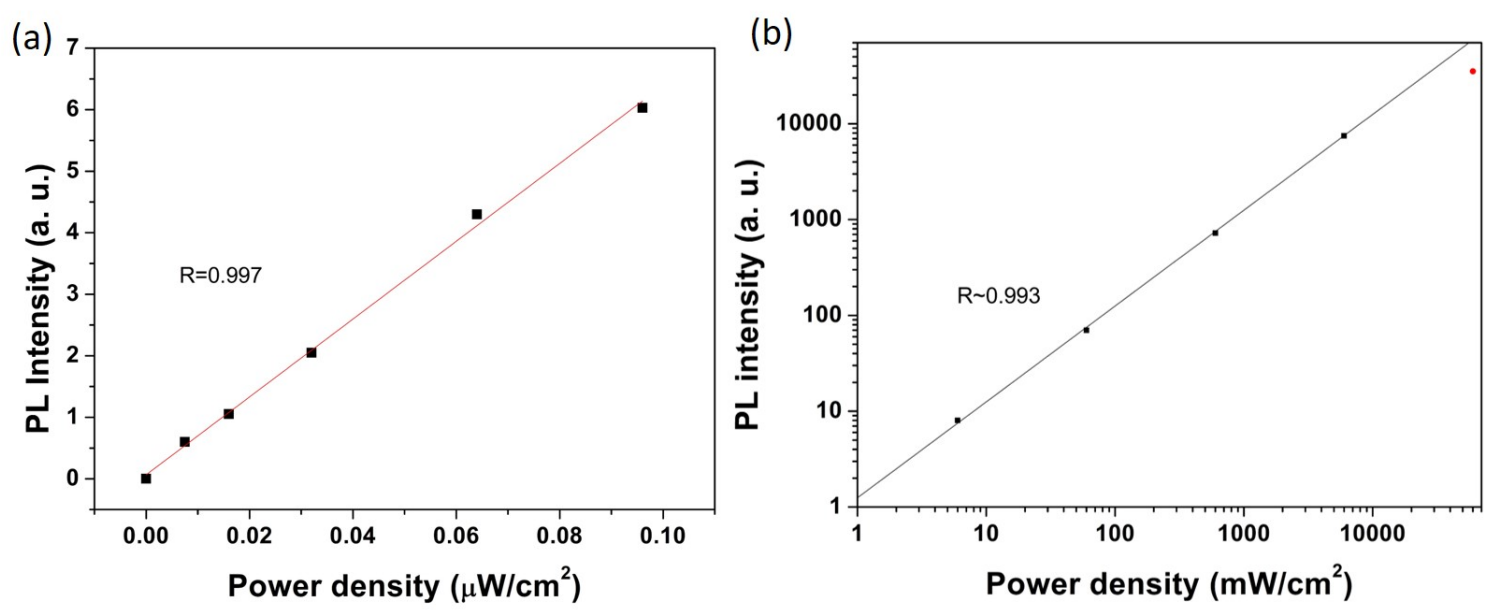

Figure S7. Power dependent PL measurement of the broad-band emission at $700 \mathrm{~nm}$ of $1 \%$ Sn-alloyed $\mathrm{PEA}_{2} \mathrm{PbI}_{4}$ crystals at low (a) and high (b) excitation power. The final red data point above 10000 $\mathrm{mW} / \mathrm{cm}^{2}$ that deviates from the linear fit is likely due to sample damage at high laser power.

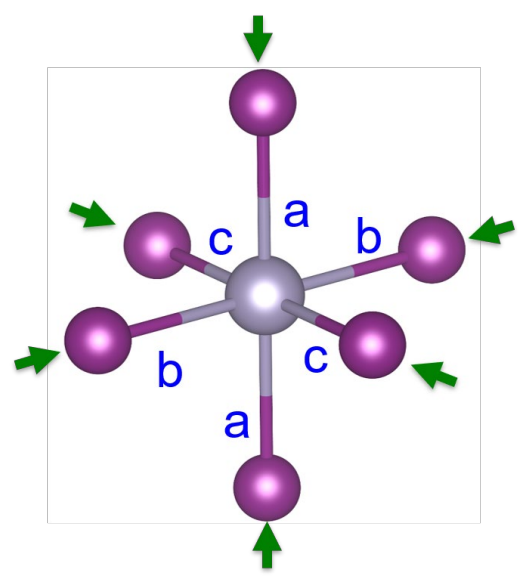

Figure S8. Illustration of $\left[\mathrm{SnI}_{6}\right]$ octahedron showing three sets of $\mathrm{Sn}-\mathrm{I}$ bonds (green arrows indication $\mathrm{Sn}-\mathrm{I}$ bond contraction direction under excitation).

Table S2. Bond distances for the ground and excited states of the SnI6 octahedron

\begin{tabular}{|c|c|c|}
\hline Bond & Ground state & Excited state \\
\hline $\mathrm{a}$ & $3.192 \AA$ & $3.027 \AA$ \\
\hline $\mathrm{b}$ & $3.196 \AA$ & $3.013 \AA$ \\
\hline $\mathrm{c}$ & $3.187 \AA$ & $3.100 \AA$ \\
\hline
\end{tabular}




\section{References:}

1. $\quad$ Chen, X.; Lu, H.; Li, Z.; Zhai, Y.; Ndione, P. F.; Berry, J. J.; Zhu, K.; Yang, Y.; Beard, M. C. Impact of Layer Thickness on the Charge Carrier and Spin Coherence Lifetime in Two-Dimensional Layered Perovskite Single Crystals. ACS Energy Lett. 2018, 3, 2273-2279.

2. $\quad$ Kresse, G.; Furthmüller, J. Efficient iterative schemes for ab initio total-energy calculations using a plane-wave basis set. Phys. Rev. B 1996, 54, 11169-11186.

3. Kresse, G.; Furthmüller, J. Efficiency of ab-initio total energy calculations for metals and semiconductors using a plane-wave basis set. Comput. Mater. Sci. 1996, 6, 15-50.

4. $\quad$ Blöchl, P. E. Projector augmented-wave method. Phys. Rev. B 1994, 50, 17953-17979.

5. $\quad$ Perdew, J. P.; Burke, K.; Ernzerhof, M. Generalized Gradient Approximation Made Simple. Phys. Rev. Lett. 1996, 77, 3865-3868.

6. Perdew, J. P.; Ernzerhof, M.; Burke, K. Rationale for mixing exact exchange with density functional approximations. J. Chem. Phys. 1996, 105, 9982-9985.

7. Wang, X.; Meng, W.; Liao, W.; Wang, J.; Xiong, R.-G.; Yan, Y. Atomistic Mechanism of Broadband Emission in Metal Halide Perovskites. J, Phys. Chem. Lett. 2019, 10, 501-506.

8. Papavassiliou, G. C.; Koutselas, I. B.; Terzis, A.; Whangbo, M. H. Structural and electronic properties of the natural quantum-well system $\left(\mathrm{C}_{6} \mathrm{H}_{5} \mathrm{CH}_{2} \mathrm{CH}_{2} \mathrm{NH}_{3}\right)_{2} \mathrm{SnI}_{4}$. Solid State Commun, 1994, 91, 695-698. 